\title{
Processing and Environmental Effects on Composite Repairs
}

\section{Faruk Elaldi \& Pelin Elaldi}

To cite this article: Faruk Elaldi \& Pelin Elaldi (2012) Processing and Environmental Effects on Composite Repairs, Materials and Manufacturing Processes, 27:3, 255-259, DOI: 10.1080/10426914.2011.577873

To link to this article: https://doi.org/10.1080/10426914.2011.577873

Accepted author version posted online: 06 Jul 2011. Published online: 06 Jul 2011.

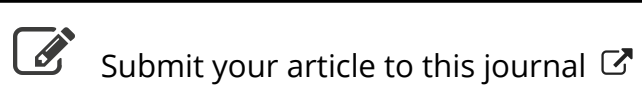

Џlll Article views: 155

Citing articles: 5 View citing articles $\square$ 


\title{
Processing and Environmental Effects on Composite Repairs
}

\author{
Faruk Elaldi $^{1}$ and Pelin Elaldi ${ }^{2}$ \\ ${ }^{1}$ Department of Mechanical Engineering, University of Baskent, Ankara, Turkey \\ ${ }^{2}$ Department of Industrial Engineering, Bilkent University, Ankara, Turkey
}

\begin{abstract}
The scarf-joint technique is one of the latest techniques used for repairing composite aircraft structures. But this technique is mostly used at depot level repairing activities since it requires autoclave and other equipments. This article focuses on scarf joint comprised of vacuum and autoclave precured and co-cured composite patches bonded to autoclave and vacuum precured parent laminates. Autoclave and vacuum cured parent laminates and scarf joints were prepared and exposed to the same temperature and moisture environment for comparison. All specimens were loaded in tension at three temperatures. Interlaminar shear strength (ILSS) tests were also carried out for the parent materials. As noted, the tensile strength and ILSS decrease when the material has been exposed to moisture and tested at elevated temperature. But, no significant difference was reported for either tensile strength or ILSS between autoclave and vacuum cured materials. The room temperature repair efficiencies are reported for single scarf repairs comprised of vacuum co-cured and precured patches. These vacuum cured repair efficiencies were found to be similar to the efficiency of the autoclave precured patch repair. This result supports the feasibility of scarf joint repairs with precured or co-cured patches under vacuum curing conditions in field level facilities. Therefore, repairs with vacuum precured or vacuum co-cured patches requiring less equipment seems to be a serious potential alternative to the composite patch repair requiring autoclave conditions which might be only available at depot level maintenance centers.
\end{abstract}

Keywords Co-cure; Composite; Effect; Environmental; Joint; Precure; Repair; Scarf.

\section{INTRODUCTION}

Composites are increasingly being used for aircraft structures because of their superior structural performance such as high strength, high stiffness, long fatigue life, and low density. Some recently developed military aircrafts like helicopters and unmanned air vehicles have nearly all-composite airframe structures. Battle damage repair (BDR) becomes significant for these structures, as they are vulnerable to ballistic impact damage from small arms fire. Therefore, a rapid repairing technique is very important either to keep the aircraft operational with a minimum level of mission capability or otherwise to send it back to depot level maintenance center. Earlier efforts to repair composite structures have generally resorted to an external lap-joint patch concept that requires autoclave facility. But, this concept may suffer from high shear and peel stresses at the ends of the patch area because of nonflushing surface [1].

By contrast, a scarf repairing technique shown in Fig. 1 seems to be more suitable for rapid repairing of composite structures since it does not require depot level capability instead it requires only a few simple hand tool, vacuum bag, and heating blanket. As a general rule, the flush scarf repair has the following advantages over an external patch, such as better strength, aerodynamic smoothness, weight, stiffness, appearances, and durability [1-13].

Received December 17, 2010; Accepted March 25, 2011

Address correspondence to Faruk Elaldi, Department of Mechanical Engineering, University of Baskent, 06530, Ankara, Turkey; E-mail: elaldi@baskent.edu.tr
However, this repair technique is still being developed. Investigations, therefore, are going to determine the environmental effects of oil, fuel, paint striper, and absorbed moisture on the repaired laminates [14-16] and also to determine the differences between the properties of vacuum bag cured and autoclave cured laminates $[4,5]$. Geometric effects including laminate material thickness, stacking order, structural form, accessibility, and protrusion limitations are also being investigated $[1,3,13,17]$.

The majority of the studies on scarf repair technique were based on depot level capabilities, i.e., autoclave curing. But, there are very limited studies on vacuum curing technique for scarf repair that could be advantageous to rapid battle damage repair in field.

Therefore, two major objectives are aimed in this study. The first one is to determine the effects of vacuum bag and autoclave curing processes on the mechanical properties of scarf repaired parent materials to indicate how these two techniques differ from each other. The second one is to determine the environmental effects, i.e., moisture uptake and service temperature $(70$ and $100 \mathrm{C}^{\circ}$ ), on the tensile and interlaminar shear strengths of repaired laminates.

\section{TEST MATERIALS AND PROCESSES}

\section{Prepreg Materials}

The material used in this study was Ciba Geigy Fiberdux $913 \mathrm{G} / 7781$ fabric prepreg, which consisted of woven glass-reinforced impregnated with epoxy resin. A film adhesive, (FM73), manufactured by American Cyanamid, was used in scarf joint-type repairs, and the 


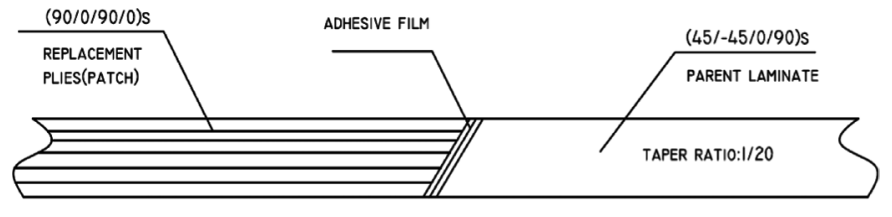

Figure 1.-Repair of a flat laminate with single scarf technique.

repairs were cured under vacuum at a temperature of $125^{\circ} \mathrm{C}$.

\section{Curing Processes}

The mechanical properties of laminates and adhesives are expected to be affected by the curing process. In this study, two curing processes for repair (autoclave and vacuum bag cure) have been used to process parent materials and patches. Patches were also processed by vacuum curing in-situ with cured parent laminates, which is generally called cocuring. The effects of each curing process and environmental exposure on the material properties have been investigated. The curing procedures developed for these two processes are given in Fig. 2.

\section{Specimen Preparation}

Parent material specimen. Glass fiber-reinforced epoxy laminates, consisting of 8 plies of fabric prepreg, were processed in either an autoclave or a vacuum bag. The stacking sequence of the laminates was $[+45 /-45 / 0 / 90]_{s}$. After cure, the panels were machined into tensile specimens with a configuration of $200 \times 25 \times 2 \mathrm{~mm}$ and interlaminar shear strength (ILSS) specimens with a configuration of $20 \times 10 \times 2 \mathrm{~mm}$ according to ASTM D3039 and ASTM D2344, respectively.

Scarf repair specimen. The parent laminates were used to evaluate repair techniques based on procured and co-cured patches. Precured scarfed patches and
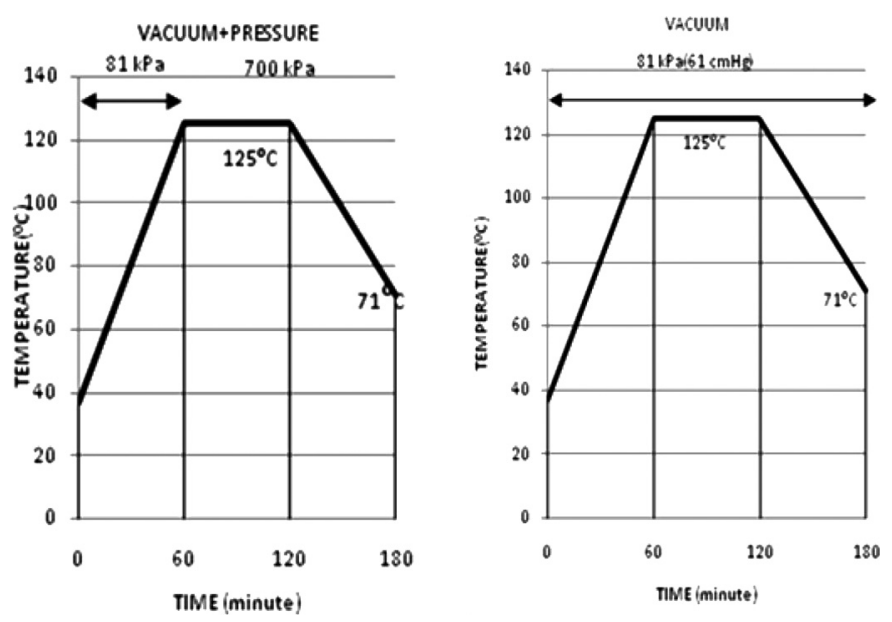

Figure 2.-Cure cycles for $913 \mathrm{G} / 7781$ prepreg material.
TABLE 1.-Types of repair

\begin{tabular}{|c|c|c|}
\hline Scarf repair & Combination & Repair process \\
\hline Repair with precured patch, A & $\mathrm{a}+\mathrm{FM} 73+\mathrm{a}^{*}$ & Vacuum \\
\hline Repair with precured patch, B & $\mathrm{b}+\mathrm{FM} 73+\mathrm{b}^{+}$ & Vacuum \\
\hline Repair with co-cured patch, C & $\mathrm{a}+\mathrm{FM} 73+\mathrm{c}^{\mathrm{x}}$ & Vacuum \\
\hline Repair with co-cured patch, D & $\mathrm{b}+\mathrm{FM} 73+\mathrm{c}^{\mathrm{x}}$ & Vacuum \\
\hline
\end{tabular}

tapered plies of prepreg were bonded to parent laminates under vacuum cure conditions.

In the preparation of a scarf joint, the scarfing of the parent laminate was accomplished with a portable power driven sander. Patch patterns with a stacking sequence of $[90 / 0 / 90 / 0]_{s}$, which were almost identical to the parent laminate (since the reinforcements were woven fabric) were precut, and some of the patches were precured as required. A layer of film adhesive (FM 73) was used for both type of the patches; see Fig. 1. The patches were easily fitted into the scarfed cut-out. The co-cured patches always provided a flush and smooth repair surface after cure. Finally, the panels were machined into tensile specimens according to ASTM D3039; see Table 1.

\section{MoISTURE CONDITIONING OF SPECIMENS}

To determine the effects of moisture uptake on the mechanical properties of the parent materials and repaired specimens, some of the specimens were conditioned in an environment controlled at $70^{\circ} \mathrm{C}$ and $85 \%$ relative humidity until they were saturated.

For the moisture conditioning, tension, and ILSS, specimens were kept in a sealable glass vessel that contained saturated calcium chloride solution. The specimens were supported from the cover plate in the humidified air space above the solution. The glass vessel was placed in an oven operating at the conditioning temperature with a variation of less than $1{ }^{\circ} \mathrm{C}$.

The specimens were weighed before, during, and after conditioning. They were removed from the vessel at predetermined intervals and placed in a transient storage box until they cooled to the ambient temperature, and then they were weighed to the nearest $10^{-3}$ gram. After the weighing, the specimens were returned immediately to the vessel. This weighing process was repeated until the equilibrium values of moisture uptake in the specimens were obtained. The weight gains were recorded as a function of time and the moisture uptake, determined as percent weight gain, was plotted versus the square root of time, see Fig. 3.

The average moisture uptakes in terms of weight gain percentages for ILSS specimens and tension specimens were $1.3 \%$ and $1.2 \%$, respectively. For the repair tensile test specimens, the average moisture uptake was approximately $1.8 \%$. It is shown that higher moisture content was obtained for the repaired parts. This was probably due to higher void content of the repaired area. 


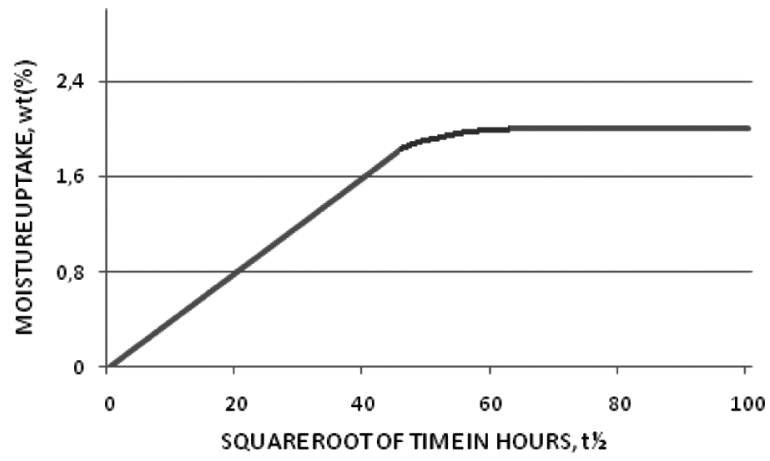

FIGURE 3.-Typical moisture uptake versus square root of time.

\section{TESTING}

\section{Tension Tests}

The tests were conducted according to ASTM D3039. A strain gage was bonded to each specimen to measure the longitudinal strain. The specimens were installed in an Instron universal testing machine using wedge grips. The strain gage and load cell outputs were collected by a computer controlled data acquisition system. A cross-head loading rate of $1 \mathrm{~mm} / \mathrm{min}$ was used. Tension tests were carried out at three temperatures: room temperature, $70^{\circ} \mathrm{C}$, and $100^{\circ} \mathrm{C}$. For the tests at elevated temperatures, an environmental chamber was used. The test temperature was preset, and the testing was initiated when the specimen reached the test temperature which required approximately 5 minutes.

The stress-strain plot for each specimen was obtained from the test data. The linear portions of the stressstrain curves were used to calculate the elastic modules. The nominal thickness and width of each specimen were used for calculating strength. The ultimate strengths for autoclave and vacuum cured specimens were obtained and utilized to calculate the efficiency of repairs at different temperatures. Repair efficiency is defined as strength of the repair expressed as a percentage of the dry parent laminate strength at room temperature. Data obtained from all tests were normalized to $60 \%$ fiber content by volume so that comparison between two cure procedures could be made.

ILSS. For the interlaminar shear strength tests, specimens were placed in a specially designed fixture to apply three point bending. Ultimate loads for calculating ILSS were determined from the load vs. displacement chart of the test machine.

\section{RESULTS AND DISCUSSION \\ Tensile Strength}

Considering the data obtained from the static tests of parent material performed at room temperature, $70^{\circ} \mathrm{C}$, and $100^{\circ} \mathrm{C}$ on dry and conditioned specimens for both autoclave and vacuum cure cycles, it can be seen that the average ultimate tensile strength $(343 \mathrm{MPa})$ of dry specimens at room temperature. for the autoclave cure

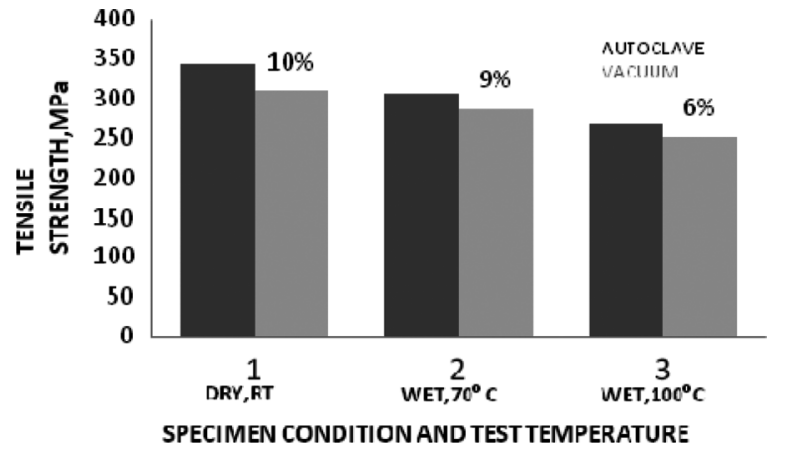

FIGURE 4.-Effect of curing process on tensile strength (RT=room temperature).

is $10 \%$ higher than the strength $(309 \mathrm{MPa})$ of dry specimens at room temperature. for the vacuum cure. The wet specimens had differences in tensile strength between the autoclave and vacuum cures of $9 \%$ and $6 \%$ at $70^{\circ} \mathrm{C}$ and $100^{\circ} \mathrm{C}$, respectively; see Fig. 4. These differences were considered insignificant and they indicated that vacuum cured patches could be an alternative to autoclave cured patches for repair in the field level maintenance facility.

It was also noted that moisture (wet) conditioned specimens showed a decrease in tensile strength of up to $8 \%$ (from $343 \mathrm{MPa}$ to $316 \mathrm{MPa}$ ) at a test temperature of $70^{\circ} \mathrm{C}$ and up to $23 \%$ (from $343 \mathrm{MPa}$ to $268 \mathrm{MPa}$ ) at $100^{\circ} \mathrm{C}$ for autoclave cured material. Similar results were also obtained for vacuum cured specimens. The maximum decrease in strength was about $23 \%$, which came from the effect of combining moisture, temperature, and curing process, see Fig. 5. Therefore, it is important in design to take the elevated temperature strength for this material into account, as the room temperature strength is significantly higher.

No significant change in strain at failure was observed in tension loading at different temperatures after moisture exposure, but a slight decrease of modulus was found to occur for both curing processes as the test temperature increased.

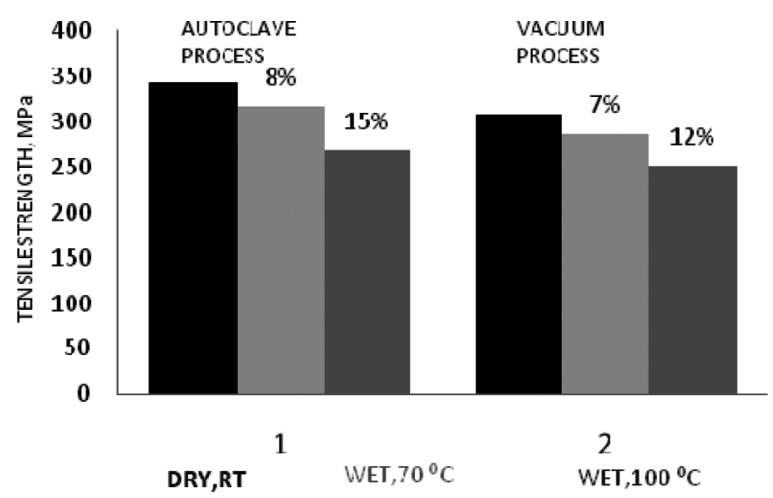

Figure 5.-Effect of moisture and temperature on tensile strength $(\mathrm{RT}=$ room temperature). 
TABLE 2.-Scarf repair ultimate tensile strength results.

\begin{tabular}{lccc}
\hline & \multicolumn{3}{c}{ Ultimate tensile strength (MPa) } \\
\cline { 2 - 4 } & \multicolumn{3}{c}{ Specimen condition and test temperature } \\
\cline { 2 - 4 } Repair & Dry, room temperature & Wet, $70^{\circ} \mathrm{C}$ & Wet, $100^{\circ} \mathrm{C}$ \\
\hline Precured scarf repair, A & $281 \pm 2.0$ & - & $45 \pm 2.0$ \\
Precured scarf repair, B & $228 \pm 2.0$ & - & $29 \pm 2.0$ \\
Co-cured scarf repair, C & $245 \pm 2.0$ & $97 \pm 25$ & $34 \pm 0.06$ \\
Co-cured scarf repair, D & $236 \pm 0.4$ & $136 \pm 9.0$ & $41 \pm 06$ \\
\hline
\end{tabular}

On the other hand, the ultimate tensile strength (UTS) of repair specimens dropped rather drastically at elevated temperatures $\left(70^{\circ} \mathrm{C}\right.$ and $\left.100^{\circ} \mathrm{C}\right)$. It is considered that this might have been due to debonding between parent material and patches. However, the difference in tensile strength between precured (A and B in Table 2) and co-cured (C and D in Table 2) repair specimens was not significant at room temperature, since bonding strength does not change with the curing technique.

At room temperature, the highest repair efficiency $(81 \%)$ was obtained for the dry scarf repair (A) with an autoclave precured patch; see Table 3 , in which the baseline data is based on dry parent material strength. With a vacuum precured patch (B), the repair specimens used in the study were capable of retaining $75 \%$ of the parent material strength; see Table 3 . The repair efficiency with co-cured patches $(\mathrm{C}, \mathrm{D})$ was also found to be approximately $75 \%$ at room temperature.

At elevated temperatures $\left(70^{\circ} \mathrm{C}\right.$ and $\left.100^{\circ} \mathrm{C}\right)$, repair efficiencies were low, and all of the failures occurred in adhesives (FM73). Upon examining the fracture surfaces (Fig. 6), a considerable number of voids and blisters can be observed. These defects may have been caused by the entrapped moisture during the conditioning. The presence of the voids is expected to contribute to the degradation of the shear strength of the adhesive. The shear strength obtained from these specimens was found to be relatively low.

On the other hand, scarf repair efficiency is generally affected by factors such as matching of plies, quality of adhesive, scarf angle, and tolerance between scarfed surfaces. In all cases, the plies in a patch must be carefully cut so that they match the surrounding laminate orientation. As a matter of fact, there is a tradeoff between precured and co-cured scarfed patch repairs. A precured scarfed patch repair (A, B) is easy to install against the prepared parent surface, it gives excellent aerodynamic smoothness for flat surfaces, and it permits

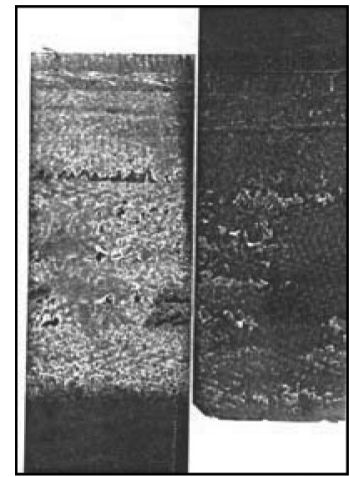

Figure 6.-A typical fracture surface of test specimen at elevated temperature $(\mathrm{RT}=$ room temperature).

TABLE 4.- Interlaminar shear strength (ILSS) of repaired specimens for two cure conditions.

\begin{tabular}{lcc}
\hline \multirow{2}{*}{$\begin{array}{l}\text { Specimen condition } \\
\text { and test temperature }\end{array}$} & \multicolumn{2}{c}{ Interlaminar shear strength (ILSS) (MPa) } \\
\cline { 2 - 3 } & Autoclave process & Vacuum process \\
\hline Dry, room temperature. & $59 \pm 0.20$ & $57 \pm 2.7$ \\
Wet, $70^{\circ} \mathrm{C}$ & $39 \pm 1.4$ & $36 \pm 2.7$ \\
Wet, $100^{\circ} \mathrm{C}$ & $26 \pm 2.7$ & $27 \pm 2.0$ \\
\hline
\end{tabular}

a high strength patch to be incorporated into the repair. However, the precured patch repair is not suitable for contoured surfaces. On the other hand, co-cured scarfed patch repair $(C, D)$ in general is useful for both flat and contoured surfaces, but it may also be suitable for repairs where access is limited to a single exposed surface.

\section{ILSS}

The ILSS values measured at room temperature, $70^{\circ} \mathrm{C}$, and $100^{\circ} \mathrm{C}$ are presented in Table 4 . The results of the short-beam three-point bend tests show that the ILSS of saturated specimens dropped considerably at test temperatures of $70^{\circ} \mathrm{C}$ and $100^{\circ} \mathrm{C}$, but no significant difference was observed between the ILSS of the autoclave and vacuum cured materials.

As indicated in tensile strength results and discussion, voids and blisters caused by the entrapped moisture during the conditioning phase may contribute to this degradation of the shear strength of the bonding at elevated temperatures.

TABlE 3.-Repair efficiencies and failure modes for specimens tested at three temperatures.

Repair efficiency, \%

\begin{tabular}{lccccc} 
Specimen condition and test temperature & Precured scarf repair, A & Precured scarf repair, B & Co-cured scarf repair, C & Co-cured scarf repair, D & Failure mode \\
\hline Dry, room temperature & 81 & 75 & 71 & 76 & material tension \\
Wet, $70^{\circ} \mathrm{C}$ & - & - & 28 & 44 & adhesive \\
Wet, $100^{\circ} \mathrm{C}$ & 13 & 10 & 10 & adhesive
\end{tabular}




\section{Conclusions}

From the present investigation of glass fabricreinforced epoxy, it is concluded that the tensile strength and ILSS decrease considerably when the material has been exposed to a combination of moisture and elevated test temperature. The maximum decrease with respect to the values at dry, room temperature test results including also curing processes is about $23 \%$ for tensile strength and about 55\% for ILSS.

But, no significant difference was found for either tensile strength or ILSS between autoclave and vacuum cure repairing techniques. Single scarf repairing technique with a vacuum cocured or vacuum precured patch gave a repair efficiency of $75 \%$, which was very close to the efficiency of the autoclave precured patch repair $(81 \%)$ at room temperature.

The repair techniques investigated in this study, specifically scarf repair with precured or co-cured patches under vacuum curing conditions can be performed in field level maintenance facilities. Vacuum curing process requiring less equipment seems to be a potential alternative to the composite patch repair requiring autoclave conditions which might be only available at depot level maintenance centers. However, these repairs are still not qualified since only limited testing has been conducted and other properties, e.g., fatigue, were not investigated yet.

\section{REFERENCES}

1. Hart-Smith, L.J. Adhesive bonded double lap joints. NASA Langley Research Center Report, NASA CR-112235, 1973.

2. Labor, J.D.; Myhre, S.H. Repair guide for large area composite structure repair. Northrop Corporation, AFFDL-TR79-3039, March 1979.

3. Wang, C.H.; Gunnion, A.J. Optimum shapes of scarf repairs. Composites, Part A 2009, 40, 1407-1418.

4. Myhre, S.H.; Beck, C.E. Repair concepts for advanced composite structures. J. Aircraft 1978, 16 (10), 78-479R.

5. Vilsmeir, J.W. Composite repair of aircraft structures. NATO AGARD Report No. 716, 1984.
6. Wang, J.; Zhou, Z.; Vodicka, R.; Chiu, W.K. Selection of patch and adhesive materials for helicopter battle damage repair applications. Composite Structures 2009, 91, 278-285.

7. Harman, A.; Wang, C.H. Improved design methods for scarf repairs to highly strained composite aircraft structure. Composite Structures 2006, 75, 132-144.

8. Wang, C.H.; Gunnion, A.J. On the design methodology of scarf repairs to composite laminates. Composites Science and Technology 2008, 68, 35-46.

9. Kieger, R.W.; Myhre, S.R. Large area composite structure repair. Northrop Corporation, AFFDL-TR-78-83, July 1979.

10. Myhre, S.H. Advanced composite repair-recent developments and some problems. In 26th National SAMPE Symposium, Los Angeles, CA, April 28-30, 1981.

11. Hall, S.R.; Raizenne, M.D.; Simpson, D.L. A proposed composite repair methodology for primary structure. Composites 1989, 20 (5), 479-483.

12. Wang, J.; Stankiewicz, M.; Zhou, Z.; Baker, A. Battle damage repair of a helicopter composite frame-to-skin junction-A sole external repair approach. Composite Structures 2010, 92, 936-949.

13. Baker, A.A. Development of a hard-patch approach for scarf repair of composite structures. Defense Science and Technology Organization, TR1892, 2006.

14. Douglas, C.D.; Pattie, E.R. Effects of moisture on the mechanical properties of glass/epoxy composites. In Advances in Aerospace Structures and Materials, Proceedings of the Winter Annual Meeting; Washington, DC, November 15-20, 1981

15. Myhre, S.H.; Labor, J.D.; Aker, S.C. Moisture problems in advanced composite structural repair. Composites 1982, 13, 289-297.

16. Clark, G.; Saunders, D.S.; Blaricum, T.J.; Richmond, M. Moisture absorption in $\mathrm{Gp} / \mathrm{Ep}$ laminates. Composite Science and Technology 1990, 39, 355-375.

17. Mall, S.; Conley, D.S. Modeling and validation of composite patch repair to cracked thick and thin metallic panels. Composites, Part A 2009, 40, 1331-1339. 